\title{
An Analysis of the Reverse Confusion of Trademark Rights
}

\author{
Guilin Gao \\ Capital University of Economics and \\ Business Law School, professor \\ gaoguilinrenda@163.com
}

\author{
Tianyi Wang \\ Capital University of Economics \\ and Business Law School, postgraduate \\ 648671116@qq.com
}

\begin{abstract}
At present, the reverse confusion cases of trademark right often appear in the justice practice in China, most of which are judged in accordance with the relevant provisions of the "Trademark Law of the People's Republic of China"; however it is difficult to avoid some problems. This paper aims to illuminate the development and overview of the reverse confusion theory of trademark law through literature research method, historical analysis method, comparative analysis method and case analysis method, starts with a typical case of " trademark case of If You are the One" and combines with the scholar's researches on the reverse confusion of trademark. This paper analyzes the shortcomings and insufficiencies of trademark legislation in China, and combines the current situation of Trademark Act to propose corresponding improvement suggestions from the aspect of legislation, hoping to enrich the theoretical research of reverse confusion of trademark right and promote the continuous improvement of trademark law in China.
\end{abstract}

Keywords-Trademark rights; Reverse confusion; "if you are the one"trademark case; Perfect suggestion

\section{INTRODUCTION}

Trademark reverse confusion is a new form of trademark infringement in recent years. It often has greater concealment and harmfulness, which will destroy the interests of the owner of the trademark, especially the small and medium enterprises, and destroy the normal market order. In recent years, with the more and more attention to the protection of trademark rights, the case of reverse confusion has occurred sometimes in the judicial practice, which has aroused the attention of the academia, the judiciary and even the public. This paper, based on the typical case "If You Are The One trademark case", puts forward some suggestions for improving the legislation of the reverse confusion of trademark rights in China's current laws, hoping to help the solution of such cases.

\section{AN OVERVIEW OF THE REVERSE CONFUSION OF TRADEMARK RIGHTS}

\section{A. Concept of the reverse confusion of trademark rights}

Different from the traditional trademark infringement, reverse confusion is a new form of trademark infringement. In the case of reverse confusion, the trademark infringer usually has a high reputation and the market influence of the infringer is usually stronger than the former trademark owner [1]. In addition, the infringer has a relatively stronger publicity, and it is easily mistaken for the consumers to think that the trademark of the trademark owner comes from the defendant or is related. It often does not cause damage to the former trademark owner, but increases the influence and popularity of the trademark owner. In some sense, reverse confusion does not directly affect the economic interests of the trademark owners. Most of the damage caused by the reverse is an indirect damage, such as the right to license and transfer the trademark.

\section{B. An analysis of trademark confusion}

Although traditional confusion and reverse confusion will infringe the rights of trademark owners and the public to a certain extent, there are some differences between them. Firstly, there is a difference in the direction of confusion. Traditional trademark confusion, that is to say the positive confusion, is the trademark infringer uses the goodwill of the trademark owner, who has a higher recognition, to make the public mistaken for the relationship between the two trademarks, thus improving the sales of their own goods and making profits for themselves. Reverse confusion is opposite to its direction. The trademark infringers are often known by the public. They usually use their own high reputation to carry out propaganda, so that the public mistaken that the former trademark is derived from the trademark infringer or is associated with it [2]. Two, there are differences in the subjective intentions of traditional confusion and reverse confusion. In the traditional trademark confusion, the infringer is generally subjectively malicious, hoping to gain the corresponding interest by usurping the greater reputation of the trademark owner. However, in the reverse confusion of trademark, the trademark infringer may be in good faith subjectively. As the trademark owners often have low public awareness, the infringer may not know whether his conduct has infringed on the trademark rights of others. Finally, the consequences of the two are different. In the positive confusion of the trademark, the trademark infringer often causes the trademark owner to suffer a certain loss, and he himself can take advantage of the reputation of the trademark owner and gain certain interests, but in the reverse confusion, the publicity of the trademark owner is small, which can even usually be raised by the trademark infringer, thus gaining some profits instead. 


\section{The impact of American judicial practice on the development of trademark reverse confusion}

There is no reference to the concept of "reverse confusion" in the traditional legal system of trademark. The word "reverse confusion" was developed by some judicial precedents of American courts in the 70s of last century. Initially, the concept was put forward by Grand Justice Holmes in 1918, but was not immediately accepted by American judicial practice. Just as the Seventh Circuit Court did not quote the concept of reverse confusion in the "Westward Coach Mfg. Co. v. Ford Motor Co. Case" in 1968, and did not support the plaintiff's claim. With the continuous development of the theory of reverse confusion, it was not until 1977 that the theory was formally accepted by the US courts. The "Big O Tire Dealers, Inc. v.Goodyear Tire \&amp; Rubber Co. case", which was decided in 1977 by the Tenth Circuit Court of the United States, is known as the origin judicial precedent of reverse confusion. The Tenth Circuit Court affirmed that the behavior of the accused caused the reverse confusion of the consumer and should be prohibited, and pointed out that the prohibition of trademark reverse confusion could protect the earlier trademark of small enterprises, and prevent large companies from using the earlier trademarks of small businesses as their own trademarks because of their reputation [3]. Later, with the repeated cases of trademark reverse confusion, all circles have paid more and more attention to the problem of reverse confusion. This theory has gradually been recognized by the American judicial circle, and some typical cases of this theory have emerged gradually.

Although the cases of reverse confusion have appeared repeatedly and the consequences are very serious, there are only some relevant cases in the United States on the reverse confusion of trademark rights in the world, and the other countries have not yet stipulated the tort model of reverse confusion in the law. In Europe, for example, there are no relevant regulations about the reverse confusion in the legal system of trademarks. European scholars generally believe that the infringement of trademark is mainly based on the fact of the trademark confusion rather than the direction of confusion. The reverse confusion of trademark rights is also not involved in our current legal system.

\section{THE JUDICIAL CASE OF TRADEMARK REVERSE CONFUSION IN CHINA: "IF YOU ARE THE ONE "CASE}

\section{A. Brief introduction of "If You Are The One case"}

At the end of 2008, the movie "If You Are The One" became fashionable for a time, so Ahuan Jin named the marriage agency as "If You Are The One", and applied for the trademark to the National Trademark Office and got approved. The service category of the registered trademark included dating and marriage introduction. And then Jiangsu TV's "If You Are The One" was broadcast. Ahuan Jin claimed that Jiangsu TV program has the same service category and program name as his trademark rights, which constitutes a trademark infringement. Therefore, Jiangsu satellite TV is prosecuted by Jin ahuan. The court of first instance hold that although the name of Ahuan Jin's marriage agency was the same as the name of the Jiangsu TV's program, the category of trademark registration of the two parties was different and belonged to different kinds. The public generally would not think the two parties are related, and it was not easy to cause confusion and the infringement was false [4]

The court of second instance held that in determining whether the two constitute a trademark infringement, factors such as the form, content and purpose of Jiangsu TV's program should be considered comprehensively, so as to make a comprehensive consideration of whether the two constitute the same or similar. Because that Jiangsu TV station beard a higher popularity and publicity than Ahuan Jin, it was easy for the public to think that the earlier trademark of Ahuan Jin came from the Jiangsu TV station or was associated with it, causing the reverse confusion.

The court of retrial held that the trademark law should protect trademark's function of identifying commodity and the source of service. Compared with the trademark involved in the case, the defendant's trademark had obvious differences in the form and color of the pattern with the earlier trademark and did not belong to the same category; in addition, the service purpose, content mode and object of "If You Are The One" program was different with the forty-fifth categories, "dating service" and "marriage introduction", of the "classification table", which will not lead to public confusion. Therefore, "If You Are The One" program does not constitute infringement in this case.

\section{B. The current judicial situation of trademark reverse confusion in China}

In the case of "If You Are The One trademark", the court did not define "reverse confusion", nor does it clearly indicated the considerations of reverse confusion. As the court's identification of "reverse confusion" was not clear, the court did not analyze the reasons for the existence of "the possibility of confusion" in the judgment.

However, in the judicial practice of our country, the judicial cases of reverse confusion are not rare. In 2000, the "ice point" case appeared, followed by the "iPad" case, the "Blue Storm" case, the "New Balance" case and so on. Although such cases have been repeated many times in practice, so far, the theory of reverse confusion of trademark rights is still not included in China's legislation. The lack of legislation leads to that in the judicial practice, the judge can only judge such cases in accordance with legal principle and positive confusion. Because of the different criteria for each judge, the same case may lead to different consequences of judgment and cause judicial injustice because of the difference between the judges in the same case.

\section{PROBLEMS OF THE REVERSE CONFUSION OF TRADEMARK RIGHT IN CHINA}

Analyzing the current status of the current legislation in China, trademark confusion is mainly stipulated in the Trademark law and the Anti-unfair Competition Law. However, there are no relevant regulations on the reverse confusion in these laws, and there are still no definite standards and contents for the identification of the reverse confusion. The problems are as follows. 


\section{A. The law does not specify the relevant regulations of reverse confusion}

Although there are some provisions on the traditional confusion of trademarks in the law of China, there is still a lack of theoretical research on trademark reverse confusion conducts. The case of trademark reverse confusion in China occurs repeatedly, but the concept of "reverse confusion" is not introduced in tour law which makes it can not be directly quoted in the judicial practice, causing great inconvenience. We can draw lessons from the relevant regulations of positive confusion, perfect the relevant system of reverse confusion in legislation, clear the scope of application, the standard and remedial measures of the reverse confusion.

\section{B. The criteria for the identification of reverse confusion are not yet unified}

In the case of "If You Are The One trademark", the court does not have a unified standard to identify the reverse confusion. The determination of infringement is mainly based on the analysis of the traditional confusion theory. No matter whether it is identified as the reverse confusion, the justices of the judges are not enough and lack of persuasion. Because of the lack of a unified standard of recognition, the result of such cases is not foreseeable.

The main features, subjective intention and objective behavior of the reverse confusion are different from the traditional positive confusion, so it is impossible to simply copy the positive confusion behavior when the reverse confusion behavior is judged, and it must have its own judgment standard [5]. But at present, there is still a controversy about this issue in our theoretical circles, and there is no unified understanding.

\section{There is irrationality in the remedial measures for the reverse confusion}

In the case of "If You Are The One trademark", when affirmed that the revere confusion constituted trademark infringement, the court of second instance ruled directly that the latter user should stop using the sign in this case. But because of the difference between reverse confusion and the positive confusion, that is the trademark owner is often a small enterprise with smaller popularity, and the infringer is often a large enterprise with higher reputation and better reputation, when dealing with such cases, the court should not only protect the trademark of small enterprises, but also take into account the investment cost of large enterprises and the interests of consumers, and find the balance of interests between small enterprises and large enterprises [6].

If not considering the related interests factors, directly judged the large enterprises of torn stop using the trademark involved in the case, the cost of operation and advertising will be cast to the winds [7]. Therefore, this remedial measure of stopping the use of trademark involved will cause huge cost waste, without increasing wealth, which violates the intention of setting up the remedial measures for tort.

At the same time, the specific amount of compensation is also a controversial issue in such cases. The enterprises involved in the reverse confusion often has a large market size and sales volume, the corresponding compensation amount is also large, but now there is no specific calculation method of the specific amount of compensation, the judges mostly exercise the discretionary power to calculate a general amount of compensation, which is lack of unified compensation standard.

\section{SUGGESTIONS OF IMPROVING AND PERFECTING OUR COUNTRY'S REVERSE CONFUSION LEGISLATION}

The behavior of reverse confusion will destroy the economic order in our country and encroach upon the interests of the infringed party. However, there is not enough attention to the reverse confusion, the theoretical research is not enough, and the judicial practice is difficult to carry out effectively [8].Therefore, it is necessary to strengthen the legislative work of the reverse confusion of trademark right.

\section{A. Establish the system of reverse confusion in legislation.}

At present, there are a number of trademark reverse confusion cases in China's judicial practice, but our current legislation has not yet specified. However, it is worth noting that the third revision of the Trademark Law of China has introduced the "confusion possibility" theory of the trademark and makes it one of the important elements of trademark infringement, which is a great progress. Then, through judicial interpretation, the "easy to lead to confusion" can be expanded to include both "positive confusion" and "reverse confusion", so that reverse confusion can also be included. The purpose of this is not only to protect the trademark exclusive right of trademark owners, but also to safeguard the legitimate rights and interests of consumers, so as to provide evidence for judges' decisions.

\section{B. Establish a unified identification standard of reverse confusion}

There is no unified identification standard of reverse confusion in China's legislation, which leads to the different standards cited by the local courts, which will lead to unjust verdict results. Therefore, it is urgent to establish a unified identification standard of reverse confusion.

For example, in the positive confusion, the subjective intention of the infringer is not the factor to be considered in the tort, but in the reverse confusion, there are still disputes in the academic circle of whether the infringer's subjective intention should be considered, and there is no unified standard of judgment. However, because of its intangible and regional characteristics, intellectual property is often infringed by the unintentional behavior of others. Therefore, the protection of trademark rights should be based on the principle of liability without fault, which is not changed by the different directions of confusion.

However, there is also the existence of malicious preemptive action in the reverse confusion. The defendant's behavior can not be considered to constitute a reverse confusion just because that the defendant infringes the exclusive right of the plaintiff's registered trademark and the defendant is more famous, and it is necessary to consider 
whether the trademark owner has a malicious preemptive action [9]. For example, the trademark owner mentioned in this article has seen the business opportunity in the film, and the registered trademark is exactly the same as the poster font, so the registration itself has the possibility of malicious snatch. Because of the development of awareness of intellectual property protection, people have increased the awareness of trademark registration, and the phenomenon of malicious snatch has occurred repeatedly. In order to maintain the order of the judiciary, it is necessary to regulate it in time [10].

\section{Stipulate reasonable remedial measures for the reverse confusion}

\section{1) The perfection for remedial measures}

Considering in the case of the reverse confusion infringement, the direct stop of applying the sign involved will cause make a larger loss for the latter user. Therefore, in the future judicial practice, can extend different treatment after considering the subjective intention of the latter user, and in the case of subjective goodwill, the court should decide that the latter should continue to use the sign involved after taking measures to prevent confusion, and if the latter user is subjective malicious, the court should stop its use of the sign involved at once. If the law not protect the latter user in good faith, that is to say that the latter user is prohibited to use the sign involved even after fulfilling all the obligations, which does not conform to the system of trademark registration in China. Therefore, considering the difference between the subjective intentions of the latter users can protect the interests of the latter users and protect the normal operation of the market.

\section{2) The determination of the amount of compensation}

As the trademark infringer is often known to the public, if the consumer mistaken the goods of the former trademark owner for the ones of the trademark infringer, they tend to be more willing to buy. In a short time, the sales of the trademark owners will increase. In the case of reverse confusion, the trademark owner gains benefits instead of being infringed. Therefore, the loss of the trademark owner can not be judged by the size of the sales volume [11]. However, if the profits obtained by the trademark infringer are the basis for compensation, it may be far more than the actual losses suffered by the former trademark owners. This high amount of compensation can easily cause the occurrence of malicious litigation, which leads to the abuse of the reverse confusion regulation.

Based on the above considerations, in the future case of reverse confusion, if the determination of the amount of compensation is involved, the royalty of trademark license can be used as the basis for determining the amount of tort compensation, which can not only make up for the defects of the standard of tort loss or the standard of tort profit, but also avoid the unreasonable determination of the amount of compensation [12].

\section{CONCLUSION}

In the current judicial practice of our country, there are many cases of reverse confusion of trademark rights and the judgment is often made in accordance with the relevant regulations of the Trademark Law of China, just as the "If You Are The One case" mentioned in this paper, which does not pay attention to the difference between reverse confusion and traditional positive confusion, and often causes the judicial injustice and inadequacy of remedial measures. This paper, based on the study of relevant cases and the studies of scholars in our country on trademark reverse confusion, analyzes the shortcomings of our country's trademark legislation and puts forward some corresponding suggestions on the legislative level combining with the status quo of the Trademark Law of China, hoping to play a certain role in the development of the trademark law in our country.

\section{REFERENCES}

[1] Geng Zhang, Nan You. Study of reverse confusion of trademark[J]. Intellectual property and Industrial development, 2012 (5): 13-18. (In Chinese)

[2] Long Chen. Understanding and application of trademark reverse confusion infringement $[\mathrm{J}]$. nomocracy and Commerce, 2016 (3): 54-56. (In Chinese)

[3] Ying Du. Theory of trademark reverse confusion component and the application [J]. Law, 2008 (10):56-63. (In Chinese)

[4] Xuelong Peng, Wei Guo. The usage of program name from the perspective of title and trademark--Comment on the case of "If You Are The One trademark"[J]. Intellectual property, 2016 (1):7-21. (In Chinese)

[5] Yonggang Xiong. The legal study of China's trademark reverse confusion system[J]. Legal system and society, 2016 (2): 52-53. (In Chinese)

[6] Wushuang Huang. The case of "If You Are The One trademark" from the perspective of reverse confusion theory and the view of rules[J]. Intellectual property, 2016 (1):29-36 .(In Chinese)

[7] Xuelong Peng, Study of trademark reverse confusion[J]. 2007 (5): 140146. (In Chinese)

[8] Song Sun, The judicial application of infringement judgment of trademark reverse confusion[J]. Electronic intellectual property, 2016 (03): 36-40. (In Chinese)

[9] Zeyuan Tang. The malicious snatch of trademark and the judgement of reverse confusion [N]. Journal of Jiangnan University, 2016 (5): 41-45. (In Chinese)

[10] Shen Li. Considerations of the "If You Are The One trademark case"[J]. Intellectual property, 2016 (1): 3-6. (In Chinese)

[11] Bo Yuan. Analysis the amount of tort compensation of the "New Balance trademark case" [J]. Chinese Trademark, 2015 (06): 13. (In Chinese)

[12] Yanan Li. The compensation for damage of trademark reverse confusion[J]. Legal system and society, 2012 (10): 99. (In Chinese) 